\title{
Areia descartada de fundição para uso em concreto de cimento Portland: análise do agregado
}

\author{
Spent foundry sand to Portland cement \\ concrete: an aggregate analysis
}

Leonardo de Brito Andrade ${ }^{1}$, Raquel Luiza Pereira Carnin ${ }^{2}$, Roberto Caldas de Andrade Pinto ${ }^{3}$

\footnotetext{
${ }^{1}$ Universidade Federal de Santa Catarina, Departamento de Engenharia Rural, Rodovia Admar Gonzaga, 1346, Itacorubi, Centro de Ciências Agrárias, UFSC, CEP 88034000, Florianópolis, SC, Brasil.

e-mail: leonardo.andrade@ufsc.br

${ }^{2}$ Tupy S.A., Joinville, Rua Albano Schmidt, 3400, Boa Vista, CEP 89227-901, Joinville, SC, Brasil. e-mail: raquel@tupy.com.br

${ }^{3}$ Universidade Federal de Santa Catarina, Departamento de Engenharia Civil, Rua João Pio Duarte da Silva, 205, Córrego Grande, CEP 88037-000, Florianópolis, SC, Brasil.

e-mail: r.pinto@ufsc.br
}

\section{RESUMO}

A areia descartada de fundição (ADF), um dos resíduos provenientes do processo de fabricação de peças e componentes em fundições, é um material rico em sílica, derivado de uma composição com areia natural, bastante fino em comparação com a matéria-prima natural corrente e classificado, pela norma brasileira NBR 10004, como resíduo classe II A, resíduo não perigoso e não inerte.

Por ter características físicas interessantes para ser utilizado como um substituinte do agregado miúdo natural na produção de materiais à base de cimento Portland, uma análise da ADF foi realizada buscando sua utilização em concretos de cimento Portland.

Após análise morfo-físico química da ADF, testes de incorporação em concretos de cimento Portland foram feitos e avaliados os desempenhos em várias proporções de substituição.

Como avaliação final, ensaios mecânicos e de lixiviação foram realizados nos concretos de ADF e os resultados indicaram que há perda de desempenho mecânico com o aumento do teor de ADF, mas essa perda pode ser considerada pequena quando comparada com o valor ambiental da utilização da ADF como substituinte ao agregado natural na produção de concretos.

Palavras-chave:Areia descartada de fundição (ADF), Concreto, Agregado, Matéria prima, Resíduo.

\section{ABSTRACT}

Spent foundry sand (ADF), one of the wastes from the process of manufacturing parts and components in foundries, is a material with a lot of silica from a mix with natural sand, thinner than natural sand and classified by the Brazilian standard NBR 10004 as waste class II A, non-hazardous and non-inert.

An analysis of the ADF was carried out with the objective of its use in concrete because it has interesting physical characteristics to be used as a substitute of the natural fine aggregate in the production of Portland cement-based materials.

After the morphological, physical and chemical analysis of the ADF, the use of ADF in Portland cement concrete was evaluated and the fresh performance (workability and fluidity) of these concretes was also tested in several substitution proportions.

As final evaluation, mechanical and leaching tests were performed on the ADF concrete and the results indicated that there is loss of mechanical performance with the increase of the ADF content, but this loss can be considered small when compared with the environmental value of the use of the ADF As a substitute for the natural aggregate in the production of concretes. 
Keywords:Spent Foundry Sand (ADF), Concrete, Aggregate, Raw materials, Waste.

\section{INTRODUÇÃO}

A utilização de subprodutos industriais como matérias-primas na produção de novos materiais é uma solução que vem permeando o desenvolvimento de novos materiais.

A construção civil, e todos os seus componentes, é um foco muitíssimo importante para a utilização de novos materiais produzidos com subprodutos industriais. Sendo que os materiais à base de cimento Portland, e mais especificamente, o concreto é um exemplo bastante estudado e já com grande aplicação nos mercados internacionais.

No processo de moldagem em indústrias de fundição de metais é utilizada uma grande quantidade de areia na produção de moldes tanto para metais ferrosos como não ferrosos. Toda areia é reciclada e reutilizada várias vezes durante o processo de fundição. Quando não se consegue mais reutilizá-la no processo de moldagem, por deficiência nas suas características físico-químicas, a areia é removida do sistema e passa a ser considerada como subproduto, conhecido como areia descartada de fundição (ADF).

Há dois tipos de areias residuais da fundição que diferem em virtude de suas composições químicas: areia verde ou areia de moldagem, onde se adiciona argila (bentonita) como componente aglomerante, e areia quimicamente ligada que utiliza polímeros/resinas como ligante das partículas de areia.

A areia verde consiste em 85 a 95\% de sílica, podendo ter até $12 \%$ de argila, 2 a $10 \%$ de adição de material carbonáceo (como por exemplo, bentonita) e de 2 a $5 \%$ de água. Já a areia quimicamente ligada consiste em 93 a 99\% de sílica e 1 a 3\% de ligante químico. Os ligantes químicos usados mais comumente são os uretanos fenólicos, as resinas epóxi e os silicatos sódicos [1].

A ADF é basicamente um agregado miúdo fino com características físico-químicas dependendo do processo de moldagem e do setor industrial gerador ligado ao tipo de metal a ser fundido. Sendo assim, a ADF pode ser utilizada em muitas aplicações tanto quanto as areias naturais ou artificiais como aterros, misturas para correções geotécnicas, misturas asfálticas e em concretos de cimento Portland, além de aplicações no campo da agricultura como material de cobertura de solo [1].

Para utilização na indústria da construção civil e infraestrutura, as características básicas da ADF gerada em fundição com metal ferroso devem ser verificadas. CARNIN [2] observou que o material residual apresentava na sua composição química teores de sílica, alumina e ferro de aproximadamente $90 \%$. O mesmo material apresentou mineralogia quartzosa, proveniente fundamentalmente da areia, com presença de mulita e hematita oriundas do pó de carvão, e presença de beidelita e montmorilonita derivadas da bentonita natural e da bentonita ativada, respectivamente. Já FIORE e ZANETTI [3] propuseram uma utilização racional da ADF de acordo com a fração granulométrica correspondente do lote ou amostra.

Deve ser dada importância à análise de toxicidade da ADF, pois este resíduo é composto por elementos químicos que poderão causar impactos ambientais. Sendo assim, o relatório FIRST [1] confirma que as concentrações de elementos presentes na maioria das areias de fundição nos processos com ferro e alumínio que utilizam a argila como aglomerante são similares às concentrações que naturalmente se encontram no solo. O conteúdo lixiviado dessas areias pode conter concentrações de elementos que excedam os padrões de qualidade da água, mas as concentrações não são diferentes das encontradas em outros materiais de construção, como solos naturais e cinzas volantes $[1,4]$.

No Brasil, de acordo com a Resolução CONSEMA 011/2008 [5] (semelhante à NR 538 [6]), a areia descartada de fundição pode ser utilizada em misturas asfálticas e artefatos de concreto sem função estrutural desde que requisitos relacionados com sua toxidade sejam atendidos.

O relatório FIRST [1] aponta na direção do aproveitamento da ADF em concretos, mas alerta que a granulometria mais fina pode afetar o consumo de cimento e de água modificando também a trabalhabilidade, a porosidade e a retração das misturas. Estas alterações nas propriedades da mistura podem acarretar um efeito negativo sobre a resistência e a durabilidade dos concretos, embora a forma mais a arredondada da ADF melhore a trabalhabilidade, reduzindo o consumo de água e de cimento em detrimento da sua característica granulométrica.

Vários autores apresentaram resultados positivos do uso da ADF em substituição ao agregado miúdo natural [7-10] e sugerem que é possível a produção de concretos de boa qualidade com ADF, bem como de outros materiais de construção utilizando a areia reutilizada.

Guney et al. [11] limitaram a incorporação da ADF em concreto de alta resistência em 10\% da massa de agregado miúdo não observando modificação das propriedades mecânicas e físicas. Os autores afirmam 
que a redução na resistência dos concretos com ADF é mais significativa em ADF com argila do que em ADF com resina ou polímeros, e justificam ressaltando que a presença excessiva de materiais argilosos nas misturas pode causar efeitos indesejáveis tais como enfraquecimento da zona de transição pasta-agregado, um aumento na demanda de água necessária, e um retardo na hidratação do cimento. Além disso, acreditam que possa ocorrer um aumento da migração de água de hidratação para o fino e, portanto, perda de água do concreto endurecido levando a um aumento dos vazios e acarretando em fissuração interna do concreto. Por outro lado, a presença dos finos pode conduzir à redução da porosidade do concreto e, tanto quanto possível, um melhoramento nas propriedades mecânicas e de impermeabilização [10-12].

Diante do exposto, o objetivo geral deste estudo foi avaliar a areia descartada de fundição (ADF) buscando obter resultados que possibilitem utilização em substituição parcial ao agregado miúdo fino natural na produção de concretos de cimento Portland para fins estruturais gerais.

Tendo em vista a diversidade de denominações, doravante a Areia Descartada de Fundição será identificada pela sigla $\mathrm{ADF}$, que compreende as seguintes identificações: resíduo areia de moldagem, matériaprima alternativa e resíduo areia de fundição.

\section{MATERIAIS E MÉTODOS}

\subsection{Areia descartada de fundição}

A areia descartada de fundição (ADF) utilizada nesta pesquisa foi coletada numa empresa localizada na cidade de Joinville, estado de Santa Catarina, sul do Brasil, após geração e saída do processo, imediatamente antes de ser transportada para o aterro sanitário. A ADF possuía como elemento aglutinante a argila bentonítica e o pó de carvão caracterizando-a como resíduo da areia verde de fundição, conforme CARNIN [2]. Após a coleta, a ADF foi devidamente acondicionada para evitar contaminação externa. Inicialmente foram realizados os seguintes ensaios para verificar a morfologia e características físico-químicas: análise da constituição química por fluorescência de raios-X, análise mineralógica por difratometria de raios- $\mathrm{X}$, análise térmica diferencial e termogravimetria diferencial, análise morfológica por microscopia eletrônica de varredura; e determinação da distribuição granulométrica por peneiramento. Para avaliar a toxidade da ADF e verificar o atendimento aos requisitos da Resolução CONSEMA 011/2008, foram realizados ensaios de caracterização e de classificação da ADF segundo a norma NBR 10004, análise química do extrato lixiviado, segundo a norma NBR 10005, análise química do extrato aquoso e análises de testes de toxicidade, conforme metodologia estabelecida pela Portaria FATMA N ${ }^{\circ} .17$, de 18 de abril de 2002 [13].

Análise de fluorescência foi realizada com o intuito de determinar quantitativamente os elementos presentes nas amostras sólidas. Utilizou-se equipamento da marca PHILIPS, modelo PW 2400. Os resultados foram interpretados com o software Semi-Q da PHILIPS, normalizados para 100\%. Esta normalização considera o resultado de uma análise de perda ao fogo, realizada em separado, onde a amostra é aquecida a $1000^{\circ} \mathrm{C}$ por um período de três horas. Foram analisadas três amostras de ADF, sendo uma amostra de ADF não moída. A Tabela 1 apresenta os resultados obtidos.

Pode-se verificar que os coeficientes de variação dos elementos principais, $\mathrm{Si}$, $\mathrm{Al}$ e $\mathrm{Fe}$ são baixos, o que reflete uma relativa constância na sua composição elementar. Por outro lado, os elementos que apresentaram altos coeficientes de variação, representam parcelas inferiores a $1 \%$ das amostras. A difração de Raios-X foi realizada através do equipamento difratômetro Philips, modelo XRD-6000 (radiação $\mathrm{Cu} k \alpha$, varredura de $2 \theta / \theta, 40 \mathrm{KV}$ e 30mA). Os difratogramas coletados, como apresentado na Figura 1, foram obtidos com o software do JCPDS (JCPDS-ICDD, 2001) e por comparação com os difratogramas "teóricos" obtidos do site mincryst. A atribuição das fases levou em consideração a possibilidade físico-química de sua formação. Percebe-se pela Figura 1 a presença apenas de quartzo.

Dados simultâneos de termogravimetria (TG) e análise térmica diferencial (DTA) foram obtidos em um analisador térmico Netzsch STA 449C. As amostras secas de ADF pesando entre 20 e 35mg foram colocadas em um cadinho de alumina e aquecida, sob atmosfera de ar sintético, em fluxo de $70 \mathrm{ml} / \mathrm{min}$, da temperatura ambiente até $800^{\circ} \mathrm{C}$ em uma taxa de $10^{\circ} \mathrm{C} / \mathrm{min}$. Experimentos similares foram realizados em atmosfera de nitrogênio. 
Tabela 1: Análises elementares por fluorescência de raios-X de amostras de ADF.

\begin{tabular}{c|c|c|c|c|c}
\hline ELEMENTOS & ADF 1 (\%) & ADF 2 (\%) & ADF 3 (\%) & MÉDIA (\%) & CV (\%) \\
\hline $\mathrm{SiO}_{2}$ & 77,41 & 77,71 & 75,62 & 76,91 & 0,01 \\
\hline $\mathrm{Al}_{2} \mathrm{O}_{3}$ & 10,58 & 9,93 & 7,97 & 9,49 & 0,14 \\
\hline $\mathrm{Fe}_{2} \mathrm{O}_{3}$ & 2,78 & 3,46 & 4,03 & 3,43 & 0,18 \\
\hline $\mathrm{TiO}_{2}$ & 0,71 & 0,91 & 0,76 & 0,80 & 0,13 \\
\hline $\mathrm{CaO}$ & 0,74 & 0,74 & 1,40 & 0,96 & 0,40 \\
\hline $\mathrm{MgO}$ & 1,21 & 1,21 & 0,49 & 0,97 & 0,43 \\
\hline $\mathrm{K}_{2} \mathrm{O}$ & 1,07 & 0,99 & 1,13 & 1,06 & 0,06 \\
\hline $\mathrm{MnO}$ & 0,05 & $N \mathrm{~N}$ & $\mathrm{ND}$ & ----- & ----- \\
\hline $\mathrm{Na}_{2} \mathrm{O}$ & 0,93 & 0,87 & 0,36 & 0,72 & 0,43 \\
\hline $\mathrm{P}_{2} \mathrm{O}_{5}$ & 0,08 & 0,10 & 1,44 & 0,54 & 1,44 \\
\hline $\mathrm{SO} \mathrm{C}_{3}$ & 1,11 & 1,04 & 2,39 & 1,51 & 0,50 \\
\hline $\mathrm{Cl}$ & 0,27 & 0,16 & 0,65 & 0,36 & 0,72 \\
\hline $\mathrm{Sr}$ & 0,15 & 0,18 & 0,15 & 0,16 & 0,12 \\
\hline $\mathrm{Ba}$ & 0,10 & 0,13 & 0,11 & 0,11 & 0,13 \\
\hline $\mathrm{Zr}$ & $\mathrm{ND}$ & 0,04 & 0,04 & 0,03 & 0,87 \\
\hline $\mathrm{P.F}$. & 2,82 & 2,52 & 3,45 & 2,93 & 0,16 \\
\hline $\mathrm{Co}$ & & & & \\
\hline
\end{tabular}

${ }^{1}$ Desvio padrão $/{ }^{2}$ Coeficiente de variação

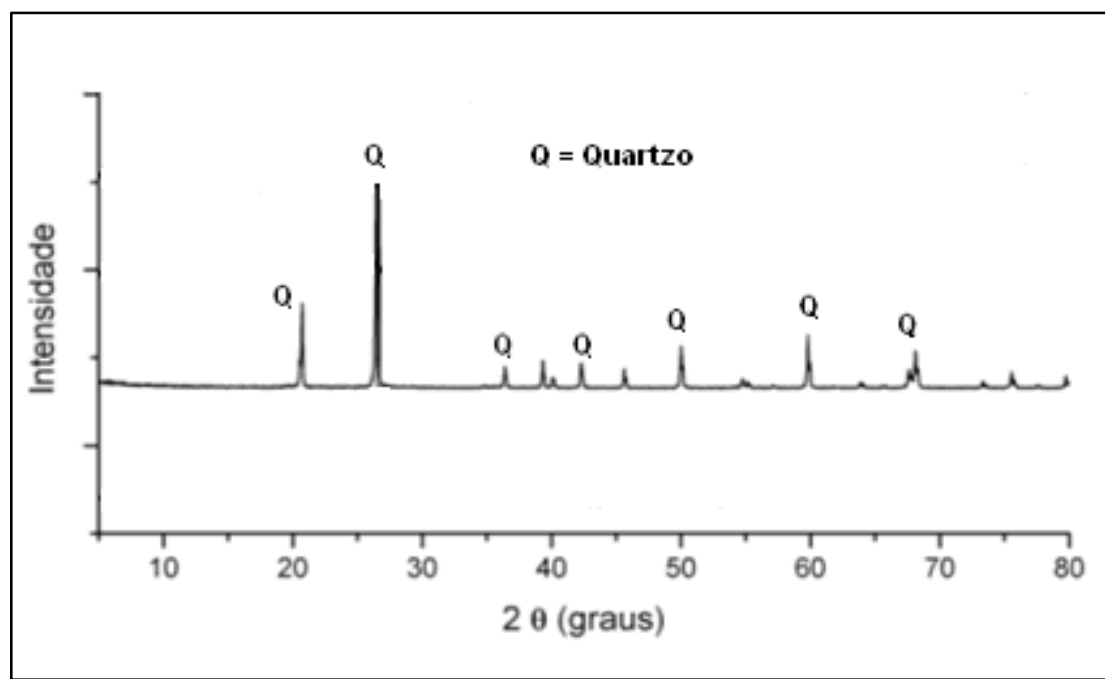

Figura 1: Difratograma de Raios-X da ADF.

Nas Figuras 2 e 3 estão expostas as curvas TG/DTA da ADF em atmosfera de ar e nitrogênio, respectivamente. 


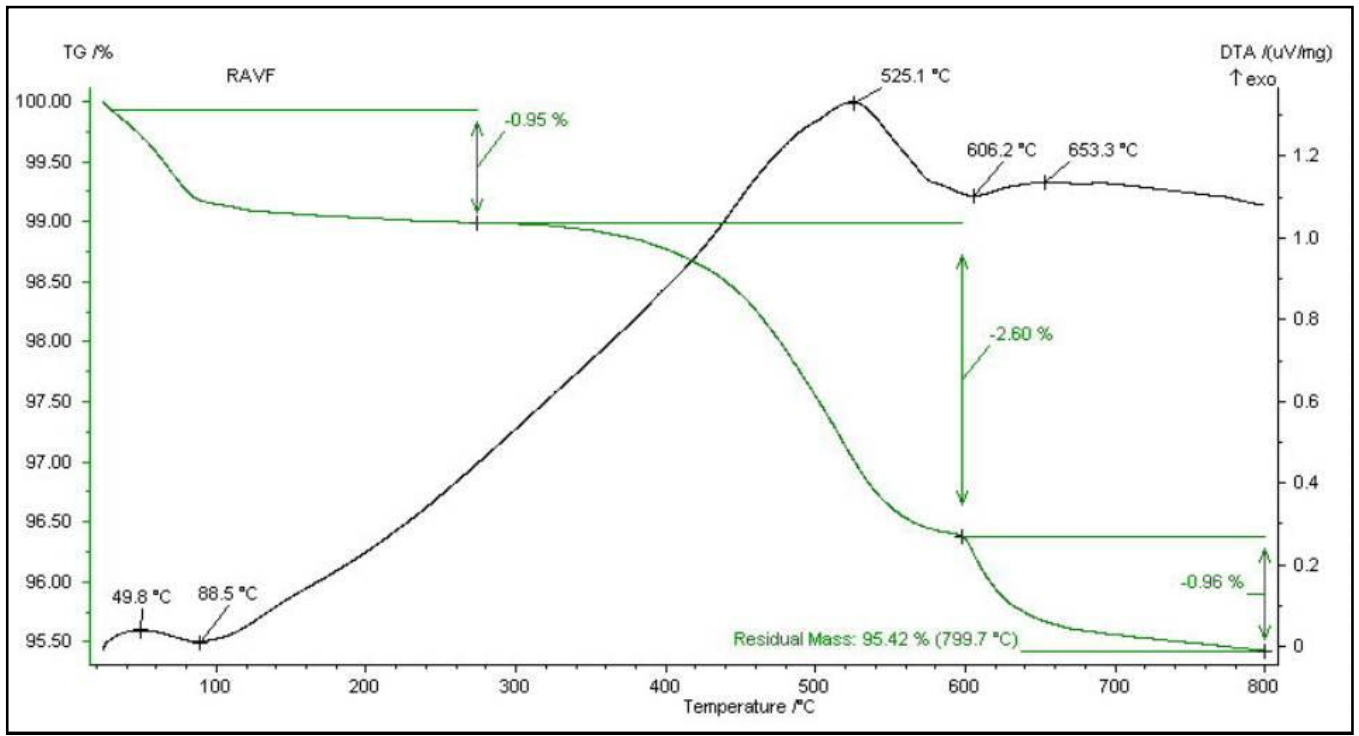

Figura 2: Análise térmica diferencial (DTA) e termogravimétrica (TG) do ADF em atmosfera de ar.

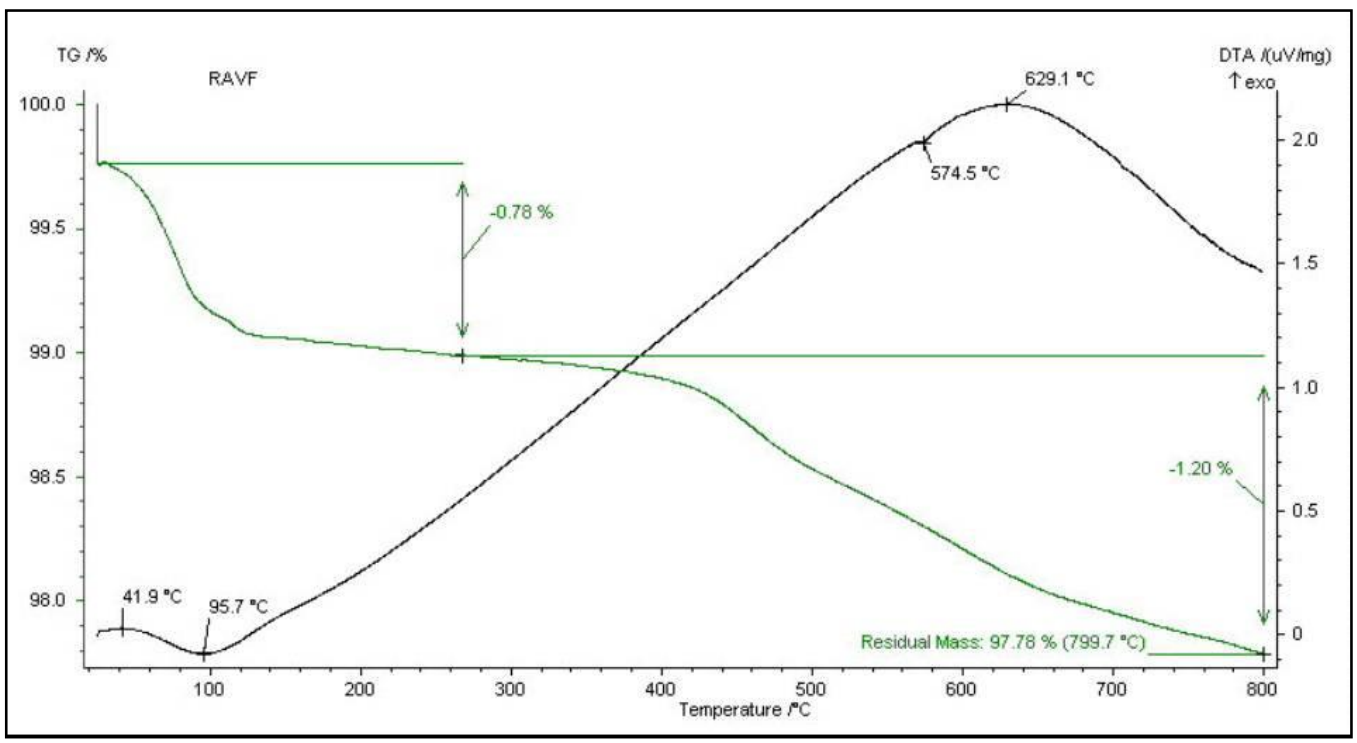

Figura 3: Análise térmica diferencial (DTA) e termogravimétrica (TG) do ADF em atmosfera inerte.

O único registro de análise de TG em ADF encontrado na literatura [14] possui atribuições similares às apresentadas neste trabalho. Espera-se que os eventos que ocorrem no ADF sejam a superposição dos eventos que ocorrem na bentonita e no carvão.

O evento de secagem da amostra está centrado em torno de $89^{\circ} \mathrm{C}$ e ficou entre $0,95 \%$. Em atmosfera de ar observa-se um evento exotérmico, centrado em $525,1^{\circ} \mathrm{C}$, atribuído à queima do carvão, seguida de um evento endotérmico, centrado em $574,5^{\circ} \mathrm{C}$, interpretado como sendo a desidroxilação da bentonita.

O estudo de caracterização da morfologia da ADF foi realizado utilizando a técnica de microscopia eletrônica de varredura, em microscópio marca Philips, modelo SEM-505. A Figura 4 apresenta a morfologia da ADF, na qual se pode observar a variação no formato do grânulo e a bentonita e o pó de carvão que recobrem o grão de sílica. 


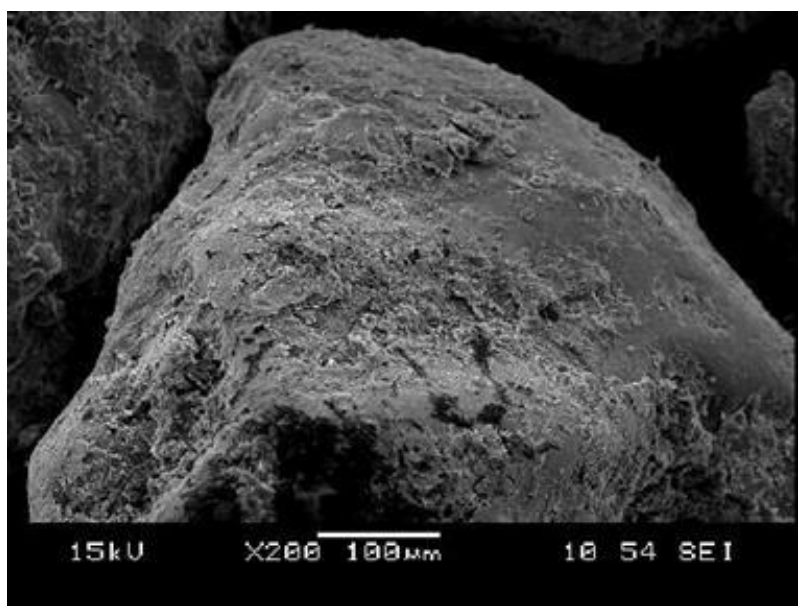

Figura 4: Morfologia da ADF.

A tabela 2 mostra os resultados da análise granulométrica da ADF enquanto a Figura 5 ilustra os resultados desta análise; consequentemente pode-se concluir que corresponde a um agregado miúdo (na ordem de 0,08 a $2 \mathrm{~mm})$.

Tabela 2: Análise granulométrica da ADF.

\begin{tabular}{c|c}
\hline PENEIRAS & MATERIALPASSANTE (\%) \\
\hline $4,8 \mathrm{~mm}: \mathrm{n}^{\circ} 4$ & 100,0 \\
\hline $2,0 \mathrm{~mm}: \mathrm{n}^{\circ} 10$ & 100,0 \\
\hline $0,42 \mathrm{~mm}: \mathrm{n}^{\circ} 40$ & 78,6 \\
\hline $0,18 \mathrm{~mm}: \mathrm{n}^{\circ} 80$ & 27,0 \\
\hline $0,074 \mathrm{~mm}: \mathrm{n}^{\circ} 200$ & 8,7 \\
\hline
\end{tabular}

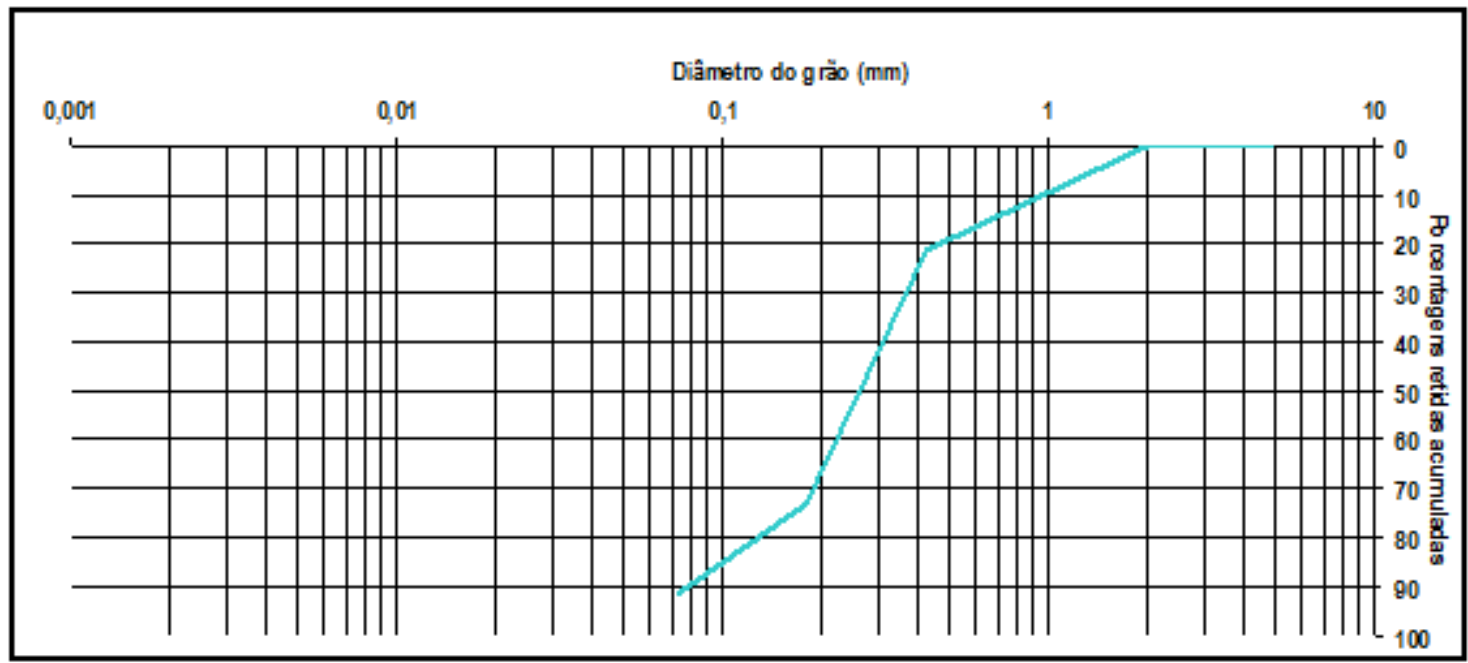

Figura 5: Análise Granulométrica da ADF.

A caracterização e classificação da ADF segundo a NBR 10004 [15] foram realizadas no Laboratório Acquaplant Química do Brasil Ltda, localizado em Joinville - SC. Os resultados estão apresentados na Tabela 3. 
Tabela 3: Parâmetros químicos no lixiviado, solubilizado da ADF pela NBR 10004.

\begin{tabular}{c|c|c|c|c}
\hline \multirow{2}{*}{ PARÂMETROS } & \multicolumn{2}{|c|}{ LIXIVIADO $(\mathbf{m g} / \mathbf{l})^{2}$ SOLUBILIZADO (mg/l) } \\
\cline { 2 - 5 } & \multicolumn{2}{|c|}{ NBR 10005 [16] $^{2}$} & \multicolumn{2}{c}{ NBR 10006 [17] } \\
\cline { 2 - 5 } & RESULTADOS & VMP $^{1}$ & RESULTADOS & VMP $^{1}$ \\
\hline Alumínio & & & 44,26 & 0,2 \\
\hline Arsênio & $<1,000 \times 10^{-4}$ & 1,0 & $3,990 \times 10^{-3}$ & 0,01 \\
\hline Bário & $<0,20$ & 70 & $<0,20$ & 0,7 \\
\hline Cádmio & $<0,001$ & 0,5 & $<0,001$ & 0,005 \\
\hline Chumbo & $<0,01$ & 1,0 & $<0,01$ & 0,01 \\
\hline Cianetos & & & $<0,005$ & 0,07 \\
\hline Cloretos & & & 49,67 & 250 \\
\hline Cobre & & & $<0,005$ & 2,0 \\
\hline Cromo Total & $<0,030$ & 5 & $<0,030$ & 0,05 \\
\hline Fenóis totais & & & 0,125 & 0,01 \\
\hline Ferro & & & 25,988 & 0,3 \\
\hline Fluoretos & $<1,000$ & 150 & $<1,000$ & 1,5 \\
\hline Manganês & & & $<0,005$ & 0,1 \\
\hline Mercúrio & $<1,000 \times 10^{-4}$ & 0,1 & $<1,000 \times 10^{-4}$ & 0,001 \\
\hline Nitrato (expresso em N) & & & 8,00 & 10,0 \\
\hline Prata & $<0,02$ & 5,0 & $<0,02$ & 0,05 \\
\hline Selênio & $<1,000 \times 10^{-4}$ & 1,0 & $<1,00 \times 10^{-4}$ & 0,01 \\
\hline Sódio & & & 127,530 & 200 \\
\hline Sulfato (expresso em SO $\mathrm{S}_{4}$ ) & & & 50,48 & 250 \\
\hline Zinco & & & 0,019 & 5,0 \\
\hline
\end{tabular}

${ }^{1}$ VMP - Valores Máximos Permitidos - ABNT NBR 10004/04.

A classificação foi realizada pela comparação dos resultados obtidos nas análises com os padrões que se encontram na Norma ABNT NBR 10.004 - Resíduos Sólidos: Anexo F - Concentração - Valor Máximo no extrato obtido pelo teste de lixiviação; Anexo G - Padrões para o teste de solubilização [15].

Segundo a comparação realizada entre o lixiviado e o solubilizado, apresentada na Tabela 3 a ADF é classificada como Resíduo Classe IIA - NÃO INERTE, em função dos elementos alumínio e ferro com valores superiores ao padrão na análise feita no solubilizado. Segundo o estudo realizado por CARNIN [2] os solos de Joinville possuem alumínio, ferro e manganês, no extrato solubilizado, acima do limite máximo permitido pela NBR 10.004 [15]. Se fossem resíduos industriais seriam classificados como Resíduo Classe II A - Não Inerte. Cabe salientar que a ADF não é um resíduo perigoso.

Seguindo os procedimentos estabelecidos na Resolução CONSEMA 011/08 [5] para utilizar a ADF em artefatos de concreto sem função estrutural esta deve apresentar concentrações de poluentes no extrato lixiviado, obtido conforme a norma ABNT NBR 10.005 [16], menores ou iguais às concentrações permitidas, conforme Tabela 4.

Tabela 4: Parâmetros químicos do extrato lixiviado da ADF pela Resolução CONSEMA 011/08 [5]

\begin{tabular}{c|c|c}
\hline PARÅMETROS & RESULTADOS & VMP $^{1}$ \\
\hline arsênio $(\mathrm{mg} / \mathrm{l})$ & $<1,000 \times 10^{-4}$ & 0,50 \\
\hline bário $(\mathrm{mg} / \mathrm{l})$ & 0,03 & 10,0 \\
\hline cádmio $(\mathrm{mg} / \mathrm{l})$ & $<0,001$ & 0,10 \\
\hline chumbo $(\mathrm{mg} / \mathrm{l})$ & $<0,01$ & 0,50 \\
\hline cromo total $(\mathrm{mg} / \mathrm{l})$ & $<0,030$ & 0,50 \\
\hline massa lixiviada $(\mathrm{g})$ & 50,025 & - \\
\hline mercúrio $(\mathrm{mg} / \mathrm{l})$ & $1,700 \times 10^{-3}$ & 0,02 \\
\hline selênio $(\mathrm{mg} / \mathrm{l})$ & $1,90 \times 10^{-3}$ & 0,10 \\
\hline
\end{tabular}

${ }^{1}$ VMP - Valores Máximos Permitidos - Resolução CONSEMA 011 de 2008 [5].

Também deve apresentar concentrações de poluentes no extrato aquoso menores ou iguais às concentrações máximas permitidas e ainda, deve apresentar $\mathrm{pH}$ na faixa entre 5,5 e 10,0. Os resultados destas podem ser visualizados na Tabela 5. 
Tabela 5: Parâmetros físico-químicos do extrato aquoso da ADF pela Resolução CONSEMA 011/08 [5].

\begin{tabular}{|c|c|c|}
\hline Parâmetros & Resultados & VMP $^{\top}$ \\
\hline cianetos $(\mathrm{mg} / \mathrm{l})$ & $<0,005$ & 2,0 \\
\hline cloretos $(\mathrm{mg} / \mathrm{l})$ & 12,53 & 2500,0 \\
\hline cobre $(\mathrm{mg} / \mathrm{l})$ & 0,015 & 2,5 \\
\hline fenóis totais $\left(\mathrm{mg} / \mathrm{l} \mathrm{C}_{6} \mathrm{H}_{5} \mathrm{OH}\right)$ & $<0,050$ & 3,0 \\
\hline ferro total $(\mathrm{mg} / \mathrm{l})$ & 6,239 & 15,0 \\
\hline fluoretos $(\mathrm{mg} / \mathrm{l})$ & $<1,000$ & 14,0 \\
\hline manganês $(\mathrm{mg} / \mathrm{l})$ & $<0,005$ & 0,50 \\
\hline massa lixiviada $(\mathrm{g})$ & 50,060 & - \\
\hline níquel $(\mathrm{mg} / \mathrm{l})$ & $<0,020$ & 2,0 \\
\hline $\mathrm{pH}$ final extrato aquoso $(-)$ & 6,88 & $5,5-10,0$ \\
\hline pH inicial extrato aquoso ( - ) & 7,95 & - \\
\hline sódio $(\mathrm{mg} / \mathrm{l})$ & 97,58 & 2500,0 \\
\hline sólidos dissolvidos totais $(\mathrm{mg} / \mathrm{l})$ & 612,0 & 5000,0 \\
\hline sulfato $(\mathrm{mg} / \mathrm{l})$ & 123,68 & 2500,0 \\
\hline sulfeto $(\mathrm{mg} / \mathrm{l})$ & $<0,050$ & 5,0 \\
\hline
\end{tabular}

${ }^{1}$ VMP - Valores Máximos Permitidos - Resolução CONSEMA 011 de 2008 [5].

Os testes de toxicidade aguda foram realizados no Laboratório de Toxicologia Ambiental da Universidade Federal de Santa Catarina.

A metodologia para realização dos testes de toxicidade aguda com os microrganismos Daphnia magna seguiu a NBR 12713/2016 [18] (baseada nos documentos ISO 5667-16:1998 "Waterquality -- Sampling -Part 16: Guidanceonbiotestingofsamples" [19] e EPA-821-R-02-012 "Methods for MeasuringtheAcuteToxicityofEffluentsandReceiving Waters toFreshwaterand Marine Organisms" [20]). Os resultados dos testes de toxicidade podem ser visualizados na Tabela 6.

Tabela 6: Resultados dos testes de toxicidade aguda com Daphnia magna.

\begin{tabular}{c|c|c|c|c}
\hline AMOSTRA & $\mathbf{p H}$ & $\begin{array}{c}\text { FATOR DE } \\
\text { DILUIÇÃO - FD }\end{array}$ & $\begin{array}{c}\text { LIMITE MÁXIMO } \\
\text { TOXICIDADE - FD }\end{array}$ & RESULTADOS \\
\hline $\mathrm{ADF}-1^{\mathrm{a}}$ réplica & 7,62 & 1 & 4 & Não tóxica \\
\hline $\mathrm{ADF}-2^{\mathrm{a}}$ réplica & 7,48 & 1 & 4 & Não tóxica \\
\hline $\mathrm{ADF}-3^{\mathrm{a}}$ réplica & 7,44 & 1 & 4 & Não tóxica \\
\hline $\mathrm{ADF}-4^{\mathrm{a}}$ réplica & 7,66 & 1 & 4 & Não tóxica \\
\hline $\mathrm{ADF}-5^{\mathrm{a}}$ réplica & 6,90 & 1 & 4 & Não tóxica \\
\hline
\end{tabular}

De acordo com os resultados foi possível verificar que a ADF atende todos os requisitos da Resolução 011/08, podendo assim ser utilizada na fabricação de artefatos de concreto sem função estrutural.

\subsection{Misturas de Concreto}

Foram produzidas misturas de concreto com relação água cimento de 0,50 e 0,60 e teor de substituição de agregado miúdo por $\mathrm{ADF}$ de $10 \%, 20 \%$ e $30 \%$, além das misturas de referência sem substituição. Esta substituição foi realizada levando-se em consideração a diferença entre massas específicas dos materiais por compensação de volume.

Diante desta proposta de substituição as características mais marcantes consideradas, além da massa específica, foram a granulometria e o teor de material pulverulento dos agregados miúdos e da ADF. A Tabela 7 apresenta as massas específicas dos constituintes e o teor de material pulverulento observado, enquanto a Figura 5 apresenta um comparativo entre a granulometria do agregado miúdo e da ADF.

As mudanças de características morfológicas e físicas do material natural para a ADF concentraram-se praticamente na incorporação sofrida pela areia de fundição, antes de ser considerada descartada, do pó de carvão e da bentonita que aumentaram a quantidade de material pulverulento.

Nota-se que a granulometria da areia fina natural é muito semelhante à granulometria da ADF. Isso faz com que a ADF seja compatível com a granulometria de um agregado natural de uso comercial. Sendo assim, pode-se concluir que há viabilidade de substituição considerando esse critério. Contudo, o teor de material pulverulento da ADF é bastante superior podendo se tornar um significativo entrave para a sua aplicação. Entretanto o material pulverulento, composto principalmente de pó de argila e/ou pó de carvão, poderia 
auxiliar no fator de compactação (empacotamento) das misturas com uma possível elevação da resistência mecânica e diminuição de diâmetro de poros capilares.

Tabela 7: Massa específica e material pulverulento dos materiais componentes dos concretos.

\begin{tabular}{c|c|c}
\hline MATERIAL & MASSA ESPECFíCIA(kg/dm $\left.{ }^{3}\right)$ & TEOR DE MATERIALPULVERULENTO (\%) \\
\hline Cimento & 2,989 & $-\cdots---$ \\
\hline Areia 1 & 2,640 & 0,3 \\
\hline Areia 2 & 2,635 & 1,4 \\
\hline ADF & 2,564 & 8,7 \\
\hline Brita & 2,891 & 0,4 \\
\hline Pedrisco & 2,769 & 0,5 \\
\hline
\end{tabular}

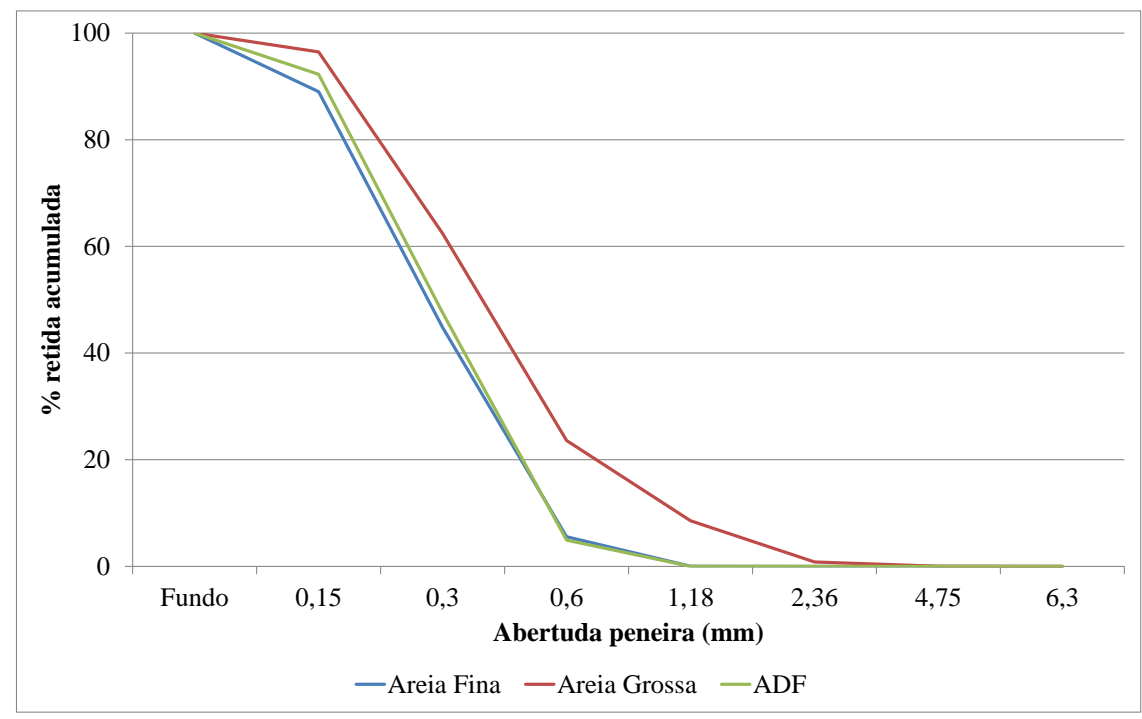

Figura 6: Curvas granulométricas comparativas dos agregados miúdos componentes dos concretos

As composições (materiais) dos concretos de ADF podem ser visualizadas na Tabela 8.

Tabela 8: Resumo dos quantitativos de materiais para a produção dos concretos de ADF

\begin{tabular}{c|c|c|c|c|c|c|c|c|c|c|c}
\hline CONCRETO & $\begin{array}{c}\text { CIMENTO } \\
\left(\mathbf{k g} / \mathbf{m}^{3}\right)\end{array}$ & $\begin{array}{c}\text { AREIA 2 } \\
\left(\mathbf{k g} / \mathbf{m}^{3}\right)\end{array}$ & $\begin{array}{c}\text { AREIA 1 } \\
\left(\mathbf{k g} / \mathbf{m}^{3}\right)\end{array}$ & $\begin{array}{c}\text { ADF } \\
\left(\mathbf{k g} / \mathbf{m}^{3}\right)\end{array}$ & $\begin{array}{c}\text { PEDRISCO } \\
\left(\mathbf{k g} / \mathbf{m}^{3}\right)\end{array}$ & $\begin{array}{c}\text { BRITA } \\
\left(\mathbf{k g} / \mathbf{m}^{3}\right)\end{array}$ & $\begin{array}{c}\text { ÁGUA } \\
\left(\mathbf{k g} / \mathbf{m}^{3}\right)\end{array}$ & $\begin{array}{c}\boldsymbol{\delta}^{1} \\
\left(\mathbf{k g} / \mathbf{m}^{3}\right)\end{array}$ & $\begin{array}{c}\mathbf{S P}^{2} \\
(\%)\end{array}$ & $\begin{array}{c}\text { SLUMP } \\
(\mathbf{m m})\end{array}$ & $\begin{array}{c}\mathbf{a} / \mathbf{c}^{3} \\
(\mathbf{k g} / \mathbf{k g})\end{array}$ \\
\hline $\mathbf{0 , 5 0 - 0 \%}$ & 438 & 339 & 339 & 0 & 429 & 643 & 219 & 2406 & 0,0 & 117 & 0,50 \\
\hline $0,60-0 \%$ & 366 & 374 & 374 & 0 & 426 & 639 & 220 & 2399 & 0,0 & 120 & 0,60 \\
\hline $\mathbf{0 , 5 0 - 1 0 \%}$ & 439 & 340 & 306 & 34 & 430 & 645 & 220 & 2415 & 0,3 & 110 & 0,50 \\
\hline $0,60-10 \%$ & 366 & 373 & 336 & 37 & 426 & 639 & 220 & 2398 & 0,5 & 100 & 0,60 \\
\hline $\mathbf{0 , 5 0 - 2 0 \%}$ & 439 & 340 & 272 & 68 & 430 & 645 & 219 & 2414 & 0,6 & 100 & 0,50 \\
\hline $0,60-20 \%$ & 367 & 374 & 299 & 75 & 427 & 640 & 220 & 2402 & 1,0 & Inadequado & 0,60 \\
\hline $\mathbf{0 , 5 0 - 3 0 \%}$ & 436 & 338 & 237 & 101 & 428 & 641 & 218 & 2400 & 0,7 & 95 & 0,50 \\
\hline $0,60-30 \%$ & 364 & 372 & 260 & 111 & 424 & 636 & 219 & 2386 & 1,0 & 90 & 0,60 \\
\hline
\end{tabular}

${ }^{1}$ massa específica $/{ }^{2}$ aditivo superplastificante $/{ }^{3}$ relação água/cimento $/{ }^{4}$ slump próximo de zero.

Foi utilizado cimento de alta resistência inicial (semelhante à ASTM C150 [21]), areia fina e média de rio e agregado graúdo granítico. O consumo de cimento e de água manteve-se praticamente constante, com uma pequena diferença não significativa entre os traços. O único parâmetro variável foi o teor de aditivo, 
pois a consistência e a trabalhabilidade variaram significativamente com o aumento do teor de ADF exigindo a incorporação de aditivo polifuncional para melhoramento da fluidez das misturas.

Como critérios básicos para validação de uma dosagem de concreto estrutural são necessárias avaliações de comportamento mecânico. O corrente é o controle da resistência à compressão e do módulo de deformação. Nesse trabalho inclui-se também a determinação da resistência à tração na flexão.

Sendo assim, foi avaliada a resistência à compressão axial [22], a resistência à tração na flexão (corpode-prova prismático $4 \times 4 \times 16 \mathrm{~cm}$ de argamassa retirada do concreto) [23] e o módulo de elasticidade [24]. Foram utilizados três corpos-de-prova para cada ensaio. Todos os ensaios foram realizados aos 28 dias.

Adicionalmente, foram realizados ensaios de evolução de valores de $\mathrm{pH}$ e de condutividade para corpos de prova prismáticos $4 \times 4 \times 16 \mathrm{~cm}$ submetidos a condição de imersão constante em água deionizada, conforme preconiza a norma NEN 7375 “Tank Test” [25].

\section{RESULTADOS E DISCUSSÕES}

As figuras 6 a 8 mostram os resultados de resistência à compressão, módulo de elasticidade e resistência à tração na flexão, respectivamente, para as misturas ensaiadas.

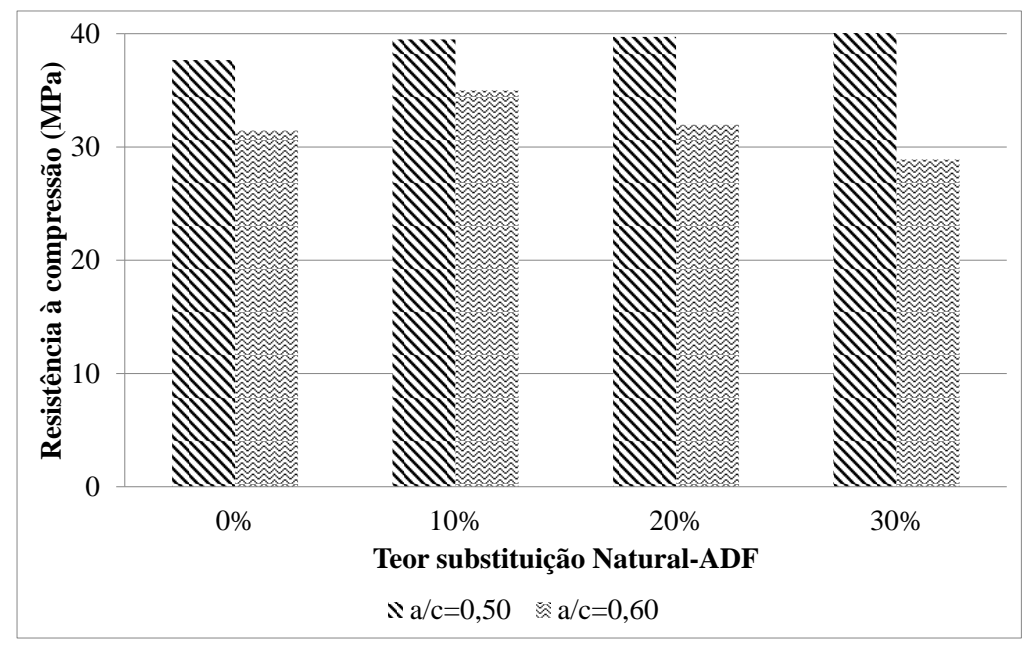

Figura 7: Resistência à compressão dos concretos de ADF

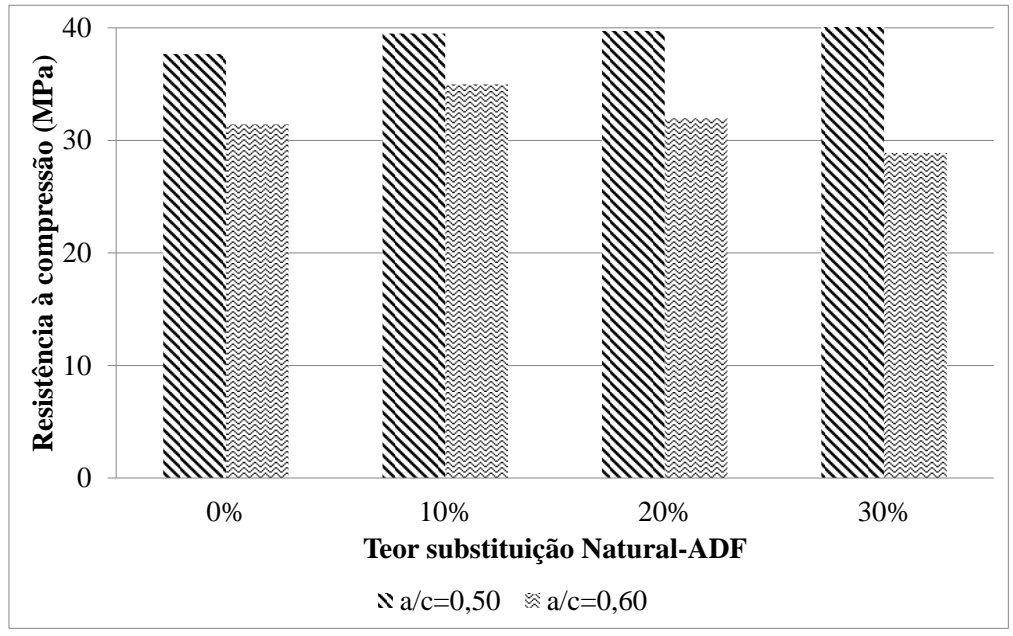

Figura 8: Módulo de elasticidade dos concretos de ADF 


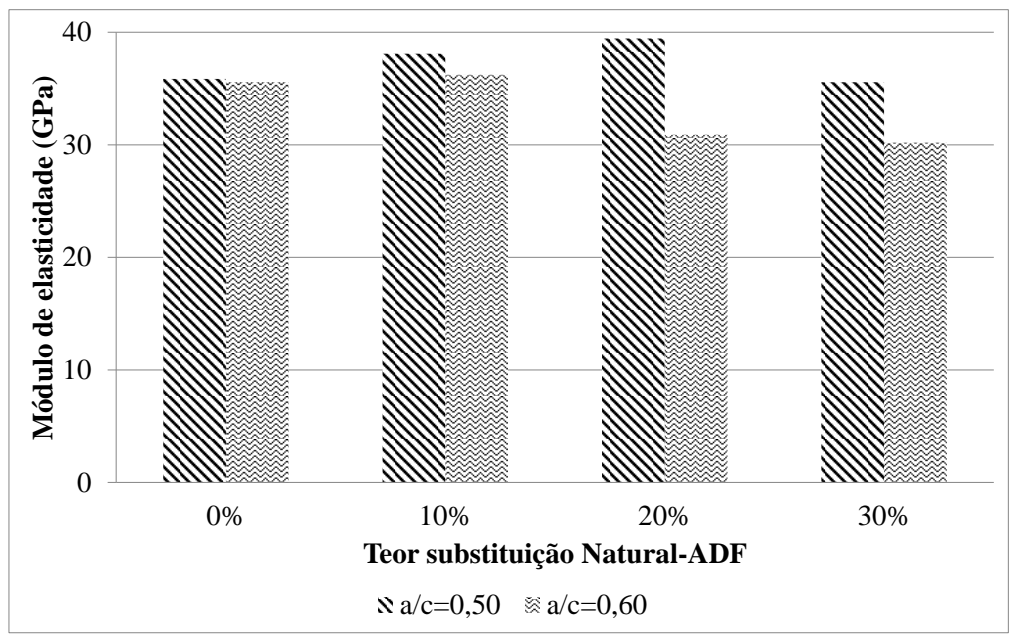

Figura 9: Resistência à tração na flexão dos concretos de ADF

Verifica-se, pela Figura 6, um pequeno acréscimo na resistência à compressão com o aumento de teor de ADF para as misturas com relação água cimento de 0,50 . O mesmo já não foi observado nas misturas com maior água cimento, onde a mistura 0,60-30\% atingiu uma resistência à compressão de aproximadamente $90 \%$ da adquirida pela mistura de referência $(0,60-0 \%)$.

Com relação ao módulo de elasticidade, só foi observado uma diminuição com relação aos valores das misturas de referência para as misturas $0,60-20 \%$ e 0,60-30\%. Este comportamento foi similar ao verificado para os valores obtidos de resistência à tração na flexão, com as misturas de menor água cimento com pouca variação (exceção da mistura 20\%) enquanto as misturas com maior água cimento sofrendo uma redução significativa nos teores de substituição de $20 \%$ e $30 \%$.

Estes comportamentos observados nas propriedades mecânicas podem ter sido ocasionados pelo elevado consumo de cimento nas misturas 0,50 , o que conduz a uma ação menos significativa do agregado na determinação destas resistências, para os níveis de resistência obtidos. Vale comentar que para concretos de alta resistência o agregado é um elemento de significativa importância, pois limita o comportamento mecânico devido à sua própria resistência mecânica e à interferência na zona de transição.

Para as misturas 0,50 , os resultados potencializam a percepção de beneficio da ADF em concretos onde o subproduto foi incorporado. Ainda que, para os diferentes teores de substituição, as reduções observadas não foram superiores a $20 \%$.

As Figuras 9 a 12 apresentam a evolução dos valores obtidos de pH e condutividade.

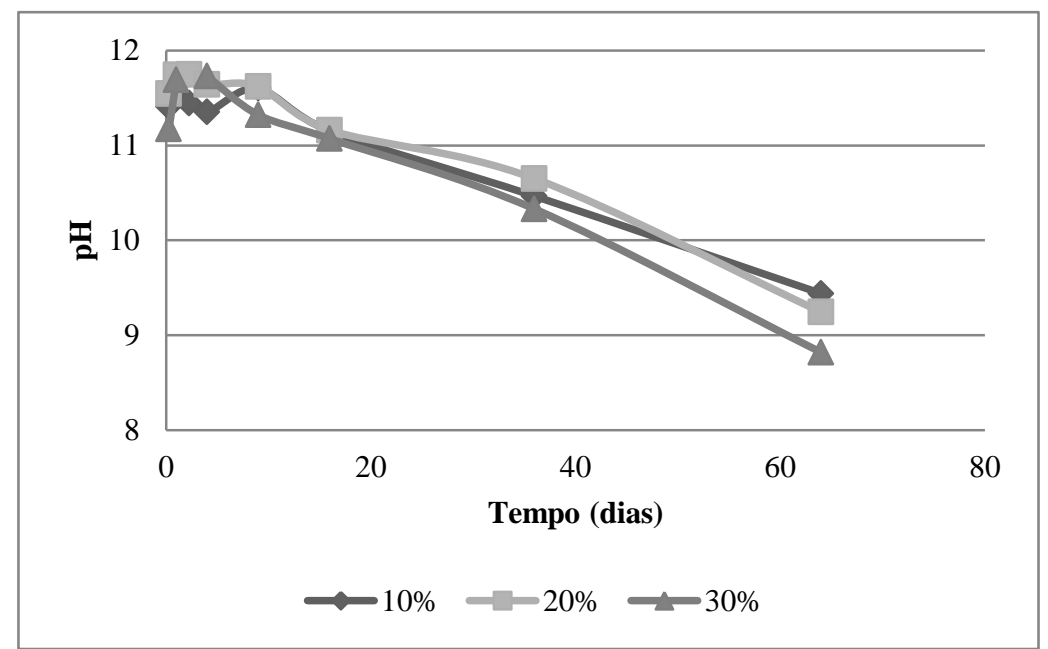

Figura 10: Evolução do pH dos extratos das misturas 0,50 submetidas ao ensaio de tanque. 


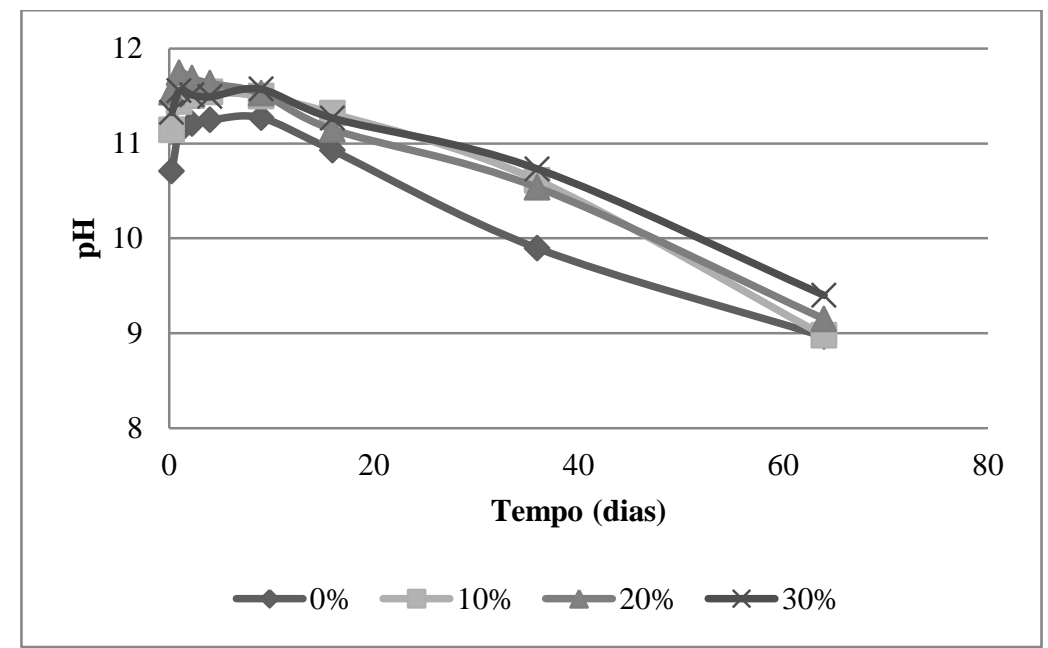

Figura 11: Evolução do $\mathrm{pH}$ dos extratos das misturas 0,60 submetidas ao ensaio de tanque.

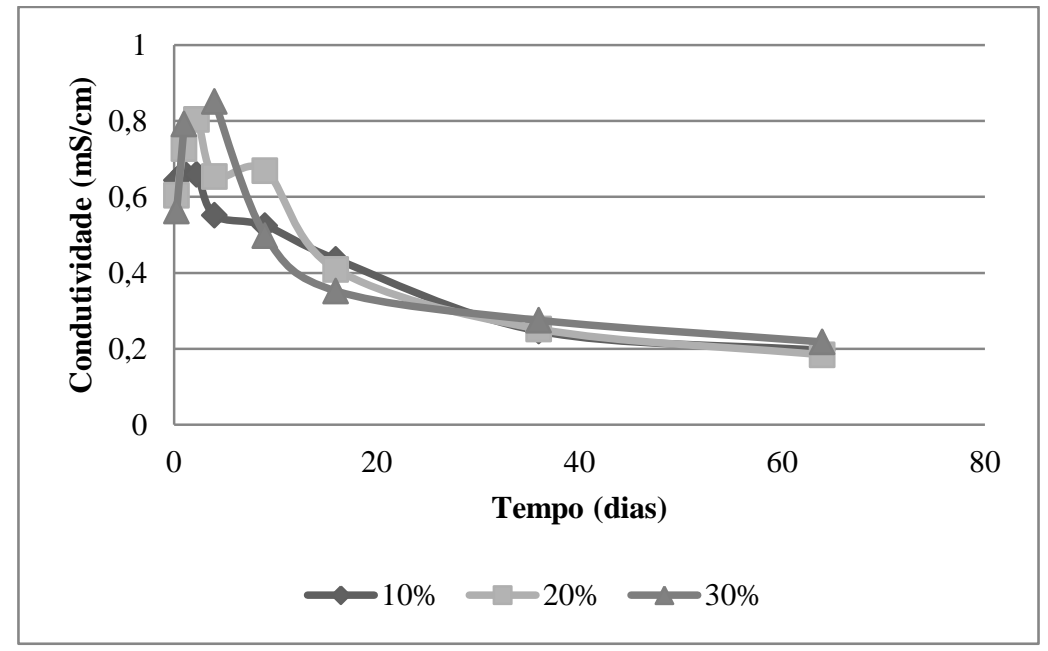

Figura 12: Evolução da condutividade dos extratos das misturas 0,50 submetidas ao ensaio de tanque.

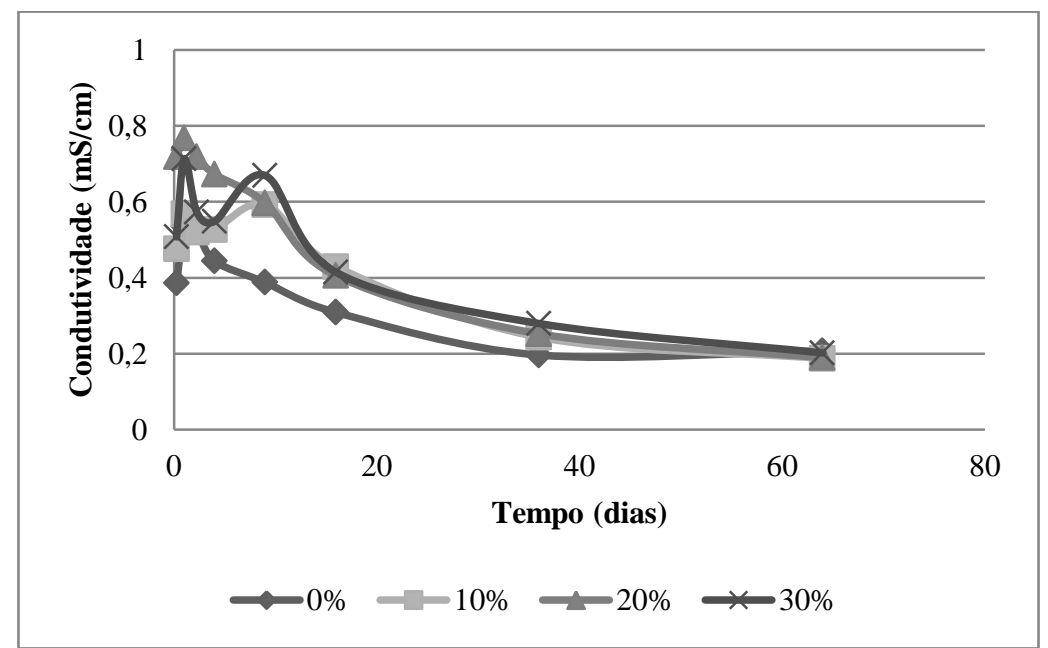

Figura 13: Evolução da condutividade dos extratos das misturas 0,60submetidas ao ensaio de tanque.

Tanto os valores de $\mathrm{pH}$ quanto os valores de condutividade nas soluções-amostras retiradas do conteúdo líquido de imersão dos corpos-de-prova de concreto de ADF não demonstraram diferenças possíveis de inferência e permitem considerar que nem a quantidade de $\mathrm{ADF}$ e nem o traço foram variáveis que alteraram 
os resultados em relação ao concreto de referência.

\section{CONCLUSÕES}

A partir dos resultados e análises efetuadas, as seguintes conclusões podem ser elencadas:

- A presença de pó de carvão e de bentonita na ADF aumentou a quantidade de material pulverulento. Esse maior conteúdo fino elevou a demanda de água e/ou aditivo redutor de água/plastificante.

- Os ensaios mecânicos de resistência à compressão, resistência à tração na flexão e módulo de elasticidade indicaram que para as misturas com relação água cimento de 0,60 houve uma leve diminuição no desempenho dos concretos com o aumento do teor de ADF. Mesmo assim, os valores não foram menores do que $80 \%$ do valor do concreto de referência.

- Nos ensaios de lixiviação, não houve modificação significativa do monitoramento de pH e condutividade das amostras coletadas ao longo do tempo.

- Por fim, os autores entendem que a utilização da ADF em concretos estruturais para usos gerais com as características semelhantes dos expostos nesse artigo poderá acontecer até um teor de $30 \%$ de substituição de ADF e relação água/cimento de 0,50.

\section{AGRADECIMENTOS}

Os autores agradecem à TUPY S.A. e ao CNPq pelo financiamento da pesquisa.

\section{BIBLIOGRAFIA}

[1] Foundry Sand Facts for Civil Engineers, Foundry Industry Recycling Starts Today (FIRST), In: Report No. FHWA-IF-04-004, Federal Highway Administration Environmental Protection Agency, Washington, D.C., 2004.

[2] CARNIN, R.L.P., Reaproveitamento do resíduo de areia verde de fundição como agregado em mistura asfáltica, Tese de Doutorado, Curso de Pós Graduação em Química, Setor de Ciências Exatas, Departamento de Química, Universidade Federal do Paraná, Curitiba, PR, Brasil, 2008.

[3] FIORE, S., ZANETTI, M.C., "Foundry wastes reuse and recycling in concrete production", American Journal of Environmental Sciences, v. 3, n. 3, pp.135-142, 2007.

[4] SIDDIQUE, R, NOUMOWE, A., Utilization of spent foundry sand in controlled low-strength materials and concrete, "Resources, Conservation and Recycling", v. 53, n.1-2, pp. 27-35, 2008.

[5] RESOLUÇÃO CONSEMA 011/08,Critérios para a utilização de ADF de materiais ferrosos na produção de concreto asfáltico e artefatos de concreto não estrutural, Secretaria de Estado do Desenvolvimento Econômico Sustentável, Conselho Estadual do Meio Ambiente - CONSEMA, Santa Catarina, 2008.

[6] NR 538 - Beneficial use of industrial byproducts, Department of Natural Resources, Wisconsin Administrative Code, 2015.

[7] SIDDIQUE, R, SCHUTTER, G., NOUMOWE, A., "Effect of used-foundry sand on the mechanical properties of concrete", Construction and Building Materials, v. 23, n. 2, pp. 976-980, 2009.

[8] SIDDIQUE, R, KAURB, G, RAJORB, A., "Waste foundry sand and its leachate characteristics", Resources, Conservation and Recycling, v. 54, n.12, pp.1027-1036, 2010.

[9] KAUR, I., Mechanical properties of concrete incorporating used foundry sand, Thesis Master of Engineering, Department of Civil Engineering, Thapar Institute of Engineering \& Technology, Deemed University, Patiala, India, 2006.

[10] NAIK, T.R., PATEL, V.M., PARIKH, D.M., et al., "Utilization of used foundry sand in concrete", Journal of Materials in Civil Engineering, v. 6, n. 2, pp. 254-263, 1994.

[11] GUNEY, Y., SARI, Y.D., YALCIN, M., et al., "Re-usage of waste foundry sand in high-strength concrete", Waste Management, v. 30, n. 8-9, pp. 1705-1713, 2010.

[12] LAWRENCE, D., MAVROULIDOU, M., "Properties of concrete containing foundry sand", In: 11th International Conference on Environmental Science and Technology, Crete, 2009.

[13] PORTARIA FATMA n ${ }^{\circ}$ 17,Estabelece os Limites Máximos de Toxidade Aguda para efluentes de diferentes origens e dá outras providências, Fundação do Meio Ambiente - FATMA, Florianópolis, SC, 2002.

[14] CANNON, F.S., VOIGT, R.C., Non-Incineration Treatment to Reduce Benzene and VOC Emissions from Greensand Systems, In: Final Report, Pennsylvania State University, 2001. 
[15] ASSOCIAÇÃO BRASILEIRA DE NORMAS TÉCNICAS - ABNT, Resíduos Sólidos - Classificação, NBR 10004, Rio de Janeiro, 2004.

[16] ASSOCIAÇÃO BRASILEIRA DE NORMAS TÉCNICAS - ABNT, Lixiviação de Resíduos - Procedimento, NBR 10005, Rio de Janeiro, 2004.

[17] ASSOCIAÇÃO BRASILEIRA DE NORMAS TÉCNICAS - ABNT, Procedimento para obtenção de extrato solubilizado de resíduos sólidos, NBR 10006, Rio de Janeiro, 2004.

[18] ASSOCIAÇÃO BRASILEIRA DE NORMAS TÉCNICAS - ABNT, Água - Ensaio de toxicidade aguda com Daphnia similis Claus, 1876 (Cladocera, Crustácea), NBR 12713, Rio de Janeiro, 1993.

[19] INTERNATIONAL ORGANIZATION FOR STANDARDIZATION - ISO 5667-16:1998, Water quality -- Sampling -- Part 16: Guidance on biotesting of samples.

[20] ENVIRONMENTAL PROTECTION AGENCY - EPA-821-R-02-012, Methods for measuring the acute toxicity of effluents and receiving waters to fresh water and marine organism, 2002.

[21] AMERICAN STANDARD TEST METHOD - ASTM C150 / C150M, Standard Specification for Portland Cement, 2017.

[22] ASSOCIAÇÃO BRASILEIRA DE NORMAS TÉCNICAS - ABNT, Concreto - Ensaios de compressão de corpos-de-prova cilíndricos, NBR 5739, Rio de Janeiro, 2007.

[23] ASSOCIAÇÃO BRASILEIRA DE NORMAS TÉCNICAS - ABNT, Concreto - Determinação da resistência à tração na flexão de corpos de prova prismáticos, NBR 12142,Rio de Janeiro, 2010.

[24] ASSOCIAÇÃO BRASILEIRA DE NORMAS TÉCNICAS - ABNT, Concreto - Determinação do módulo estático de elasticidade à compressão, NBR 8522, Rio de Janeiro, 2008.

[25] EA NEN 7375, Leaching characteristics of molded or monolithic building and waste materials. Determination of leaching of inorganic components with the diffusion test, Netherlands Normalization Institute Standard, 2004. 